\title{
Carotid Artery Stenosis Associated with Increased Mortality in Patients who Underwent Coronary Artery Bypass Grafting: A Single Center Experience
}

\author{
Marcelo P. da Rosa*, Ricardo Schwendler, Rodrigo Lopes and Vera L. Portal
}

Department of Atherogenesis and Thrombosis of the Instituto de Cardiologia do Rio Grande do Sul/Fundação Universitária de Cardiologia, Brazil

\begin{abstract}
Background: Vascular disease resulting from arteriosclerosis is a severe worldwide health risk. Early diagnosis and intervention is important to control adverse cerebral and cardiovascular events. The aim of this study was to assess the potential predictors of mortality in patients submitted to coronary bypass surgery.

Methods: Cohort study included asymptomatic cerebrovascular disease patients scheduled for coronary artery bypass grafting admitted to the cardiology reference center. All patients were submitted to carotid artery ultrasound assessment prior to surgery and were followed up during the entire in-hospital postoperative period. Carotid artery stenosis was considered clinically significant when cross sectional area $\geq 50 \%$. Significance was set at $\mathrm{p}<0.05$. Logistic regression was used to identify independent predictors of mortality.

Results: Of 455 patients with a mean age of 62.2 years $65.6 \%$ were males. The prevalence of carotid artery stenosis was $18.7 \%$. It was absent in $3.6 \%$ of the patients, below $50 \%$ in $77.8 \%$, between 50 and $69 \%$ in $11.6 \%$, and between 70 and $99 \%$ in $6.9 \%$. The carotid artery was occluded in $0.2 \%$ of the sample. An overall mortality of $12 \%$, affecting 35 men $(P=0.001)$ with stenosis $\geq 50 \%$. After logistic regression analysis, carotid artery stenosis $\geq 50 \%$ was confirmed as being an independent predictor of mortality $(P=0.005)$.

Conclusion: In this series carotid artery stenosis showed a high prevalence in the sample assessed and was an independent predictor of mortality.
\end{abstract}

Keywords: Carotid arteries; arteriosclerosis; coronary artery pathology; coronary artery bypass grafts; stroke; ultrasound.

\section{INTRODUCTION}

Coronary artery bypass grafting $(\mathrm{CABG})$ is one of the main treatment modalities in the management of patients with coronary artery disease (CAD) [1]. Several potential postoperative complications are associated with the procedure, the outcomes of which have direct implications on secondary prevention and cardiovascular rehabilitation [2,3].

The identification of clinically significant carotid artery stenosis (CAS) prior to surgery allows the surgical approach to be modified and thereby reduce mortality with acceptable risks and costs [4]. Till now, the available information is insufficient to claim that carotid endarterectomy either preceding or carried out in conjunction with $\mathrm{CABG}$ is efficient in the prevention of postoperative strokes in CAD patients [5-7]. On the other hand, carotid artery ultrasound has been referred to as an effective, safe, and widely accepted tool for the diagnosis of CAD [8], but has not been approved for use in the routine examination of patients scheduled for CABG.

\footnotetext{
*Address correspondence to this author at the Instituto de Cardiologia do Rio Grande do Sul/ FUC. Unidade de Pesquisa Marcelo Pereira da Rosa Av. Princesa Isabel, 370 - Santana, Porto Alegre, RS, 90620-001, Brazil;
} Tel/Fax: 55-51-32303757; E-mail: marcelopdarosa@gmail.com
It is certainly an interesting and important issue with multiple controversies as to nonselective screening for CAD in patients scheduled for $\mathrm{CABG}$, and the clinical significance as to the overall outcome. Taking into consideration the scarcity of papers on the topic, the aim of the present study was to assess the potential predictors of in-hospital death CAS prevalence using carotid artery ultrasound in patients scheduled for CABG.

\section{MATERIALS AND METHODS}

This cohort study included consecutive asymptomatic patients with cerebrovascular disease admitted to the cardiology reference center and scheduled for CABG (elective and non-elective) between May 2010 and April 2011. Patients underwent preoperative tests for CAS. The primary outcome to be assessed was death.

All patients included in the study signed an informed consent form. The study protocol was approved by the local Research Ethics Committee.

\section{PATIENTS}

Specific criteria for the indication of surgery were: CAD affecting the left main trunk, stenosis $>70 \%$ in the anterior 
descending artery, combined anterior descending and circumflex artery stenosis, combined left and right coronary artery stenosis or diffuse $\mathrm{CAD}$, incapacitating chest pain despite maximal medical therapy, ischemia or progressive cardiac infarction, and no response to optimal clinical treatment $[1,2]$.

Patients with indication for concomitant surgery (CABG and carotid endarterectomy), atrial fibrillation and use of anticoagulant agents, were excluded from the study.

\section{STUDY PROCEDURES}

On admission, patients were asked to answer a questionnaire designed to obtain detailed current and previous medical information: presence of personal and family risk factors, i.e., history of cardiovascular disease (CVD) in first-degree relatives (father, mother, uncles, grandparents, siblings), less than 50 years of age for women and 60 years for men; presence of hypertension (blood pressure $\geq 140 / 90 \mathrm{mmHg}$ or use of anti-hypertensive agents); dyslipidemia (total cholesterol $>200 \mathrm{mg} / \mathrm{dL}$ and/or triglyceride $>150 \mathrm{mg} / \mathrm{dL}$ or use of antilipidemic drugs); diabetes (controlled with diet; use of antidiabetic agents or insulin; fasting glucose $\geq 126 \mathrm{mg} / \mathrm{dL}$ ); obesity, i.e., body mass index (BMI) $\geq 30 \mathrm{~kg} / \mathrm{m}^{2}$ (weight in $\mathrm{kg}$ divided by height in square $\mathrm{m}$ ); peripheral vascular disease (PVD) (intermittent claudication or pain at rest and ankle brachial pressure index $\leq 0.9$ ); tobacco-smoking, including daily and occasional use of cigarettes, cigars or pipes, classification as never-smoker, previous smoker (quit smoking one month prior to hospital admission), and active (current) smoker; renal failure (creatinine $\geq 1.5 \mathrm{mg} / \mathrm{dL}$; chronic obstructive pulmonary disease (COPD) (clinical examination, use of bronchodilator treatment and chest $\mathrm{X}$ ray); and medications in use.

\section{COLOR-DOPPLER ULTRASOUND}

Exams were carried out using GE Logiq 500 (General Electric Medical Systems, Milwaukee, USA) by a specialized physician trained in vascular radiology, blinded as to information on the patients' clinical history and physical exam data using a Duplex scanner with a 7.5-MHz B-mode and a 5-MHz Doppler probe. Cross sectional area of CAS was considered as clinically significant when $\geq 50 \%$.

\section{FLOW ABNORMALITIES CORRELATED WITH THE DEGREE OF CAS}

The identification and quantification of stenosis were based on linear stenosis $[9,10]$. The stenoses were graded according to the European Carotid Surgery Trial (ECST) [11].

\section{FOLLOW-UP}

Stroke diagnosis was based on clinical symptoms (assessed by a neurologist or intensivist) and CT data. Stroke was defined as the occurrence of focal or global neurological deficit (dysarthria, dysphasia, hemiparesis, hemiparesthesia, monocular blindness) for over 24 hours caused by damage to brain structure. All patients underwent a systematic neurological examination before and after surgery.
Other clinical outcomes analyzed were: cardiogenic shock; intra- and postoperative myocardial infarction - diagnosis confirmed by presence of two of the following factors: new Q waves on two or more ECG leads [12], CK-MB $>4$ times the upper normal limit [13] or new segmental cardiomyopathy with akinesis on echocardiogram [14]; prolonged mechanical ventilation $(>48 \mathrm{~h})$; prolonged use of vasopressors $(>48 \mathrm{~h})$; sepsis; general infections (respiratory and urinary infection, endocarditis, surgical wound infection, and mediastinitis); respiratory infection (diagnosis based on chest $\mathrm{X}$ ray, leukocyte count, and compatible clinical findings); congestive heart failure; need for percutaneous transluminal coronary angioplasty; reoperation; conduction disorders requiring a temporary pacemaker; major bleeding (blood flow at the chest tubes over $10 \mathrm{~mL} / \mathrm{kg} / \mathrm{h}$ in one hour, 5 $\mathrm{mL} / \mathrm{kg} / \mathrm{h}$ in three consecutive hours, or $100 \mathrm{~mL} / \mathrm{h}$ in four hours); pericarditis; fibrillation or atrial flutter.

\section{STATISTICAL ANALYSIS}

Continuous variables were expressed as means \pm standard deviation (SD) and compared using the two-tailed Student's t-test. Two-tailed Mann-Whitney U test was used for variables with a non-normal distribution. Qualitative variables were expressed in absolute values and percentages. The median was used for variables with a non-normal distribution.

The chi-square and Fisher's exact tests were used to compare categorical variables in the univariate analysis (patients without CAS and CAD vs. patients with simultaneous CAS and CAD).

Odds ratio (OR) at $95 \%$ confidence intervals (CI) were calculated for each risk factor assessed, with the corresponding $\mathrm{p}$ value. Correlation limits were determined taking into consideration a $5 \%$ error.

Any variable that achieved a $P$ value $\leq 0.20$ in the univariate analysis was entered for analysis by multivariate logistic regression to determine independent predictors of mortality.

Significance was set at $P<0.05$. Analyses were performed using SPSS ${ }^{\circledR}$ version 18.0 software (IBM, Armonk, New York, USA).

\section{RESULTS}

Five of the 455 patients included in the study were lost: patients required urgent $\mathrm{CABG}$, performed on weekends or holidays. As a result, a total of 450 patients were analyzed.

Mean age $( \pm \mathrm{SD})$ in the sample was $62.2 \pm 9.4$ (range: 38 to 85 years); $65.6 \%$ (295) of the patients were male, and 94.2\% (424) were Caucasian. Baseline clinical characteristics and comorbidities are listed in Table $\mathbf{1 .}$

All surgical procedures were carried out with cardiopulmonary bypass (CPB), and $85.3 \%$ (384) of the surgeries were elective. Intraoperative complications were present in 2.7\% (12) of the cases: major bleeding, ventricular arrhythmia, pre-CPB cardiac arrest, post-CPB cardiac arrest, total atrioventricular block, and death. 
Table 1. Clinical Characteristics and Comorbidities Present at Baseline in Relation to Carotid Stenosis Degree

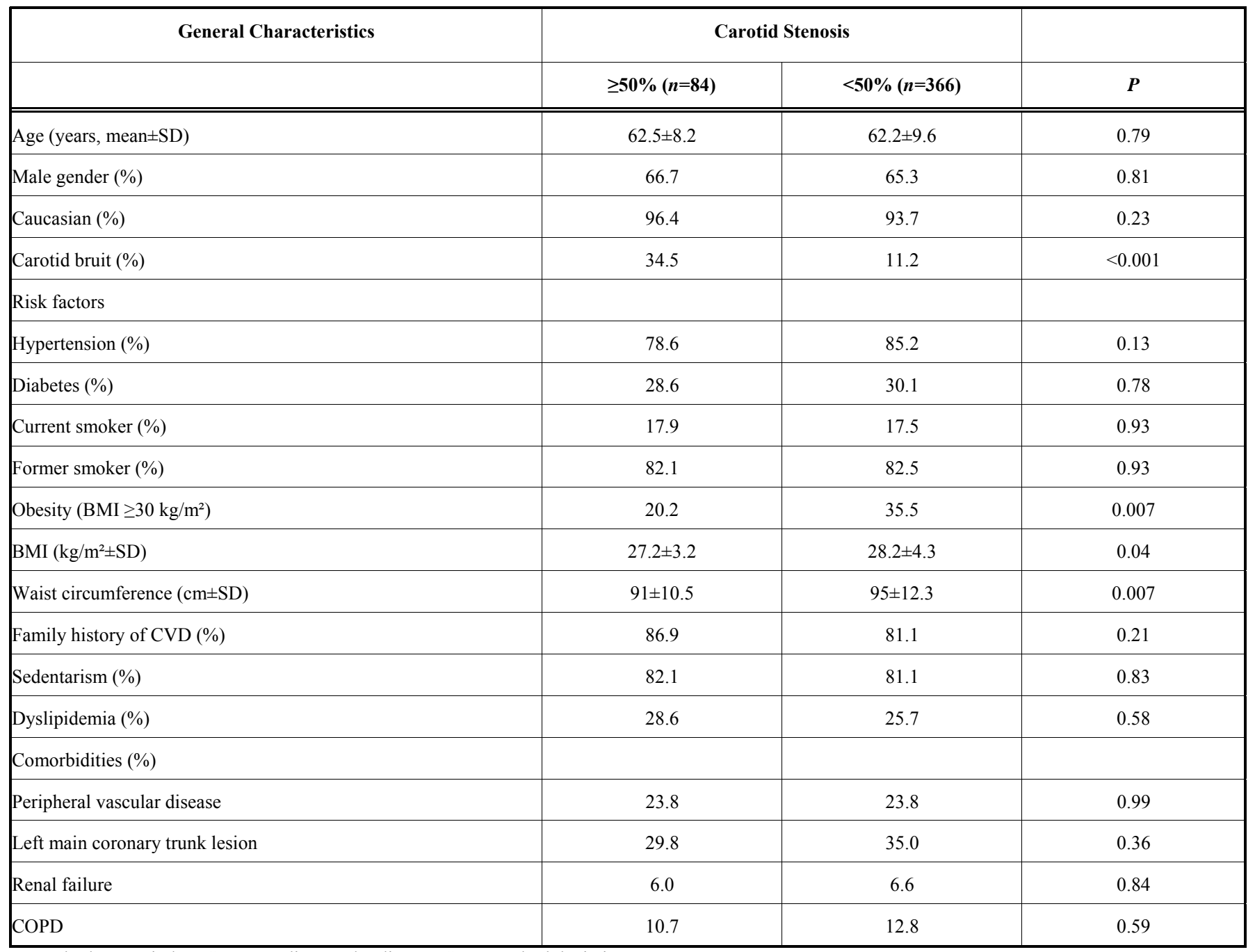

$\mathrm{BMI}=$ body mass index; $\mathrm{CVD}=$ cardiovascular disease; $\mathrm{SD}=$ standard deviation.

The main postoperative complications observed in the present sample were: cardiogenic shock in $1.1 \%(5)$, use of vasopressors for more than 48 hours in $4.9 \%$ (22), mechanical ventilation for more than 48 hours in $5.1 \%$ (23), sepsis in $1.8 \%(8)$, respiratory infection in $3.6 \%$ (16), urinary infection in $0.4 \%$ (2), and uncontrolled hypertension in $0.7 \%$ (3).

Personal and family history were distributed as follows: CVD in $82.2 \%$ (370), left main coronary stenosis in $34 \%$ (153), obesity in $32.7 \%$ (147), diabetes in $29.8 \%$ (134), PVD in $23.8 \%$ (107), COPD in $12.4 \%$ (56), and renal failure in $6.4 \%$ (29). In spite of the differences observed in several variables with regard to degrees of CAS, none reached statistical significance, except for the clinical finding of carotid bruit $(P<0.001)$.

With regard to degree of CAS, $77.8 \%$ (350) of the patients presented stenosis $<50 \%, 11.6 \%$ (52) presented stenosis between 50 and $69 \%, 6.9 \%$ (31) between 70 and $99 \%$, and $0.2 \%$ (1) presented occlusion. Ultrasound was normal in $3.6 \%$ (16) of the sample. Of the patients with stenosis $\geq 50 \%$, $66.7 \%$ (56) were male
Carotid bruit was detected in $34.5 \%$ (29) of the patients with CAS $>50 \%$ and in $11.2 \%$ (41) of those: $<50 \%$. The presence of carotid bruit had a sensitivity of $34.5 \%$, specificity of $88.8 \%$, positive predictive value of $41.4 \%$, negative predictive value of $85.5 \%$, positive likelihood ratio of $3.1 \%$, and negative likelihood ratio of $0.73 \%$ for CAS. The OR for carotid bruit was $4.24(95 \% \mathrm{CI} 2.36-8.40)$ times higher in patients with CAS $(P<0.0001)$.

We observed an overall mortality of $12 \%$ (54), affecting 35 men $(\mathrm{p}=0.001)$ with $\mathrm{CAS} \geq 50 \%$. Median hospital stay after surgery was 11 days (2-80). Median operating time was 4 hours and 15 minutes (1:45-8:15).

In the univariate analysis, the OR for the occurrence of neurological outcomes and mortality in patients with CAS $\geq 50 \%$ was as follows: 1.5 for psychomotor agitation; 4.9 for cognitive abnormalities; 2.1 for stroke and 2.7 for death (Table 2).

The predictors of mortality identified in the univariate analysis: CAS $\geq 50 \%$; obesity; renal failure; and left main coronary trunk lesion. 
Table 2. Neurological Outcomes and Mortality According to Carotid Stenosis Degree

\begin{tabular}{|c|c|c|c|c|c|c|c|}
\hline \multirow[t]{3}{*}{ Clinical Outcome } & \multicolumn{4}{|c|}{ Stenosis Degree } & \multirow[t]{3}{*}{ OR } & \multirow[t]{3}{*}{$\boldsymbol{P}$} & \multirow[t]{3}{*}{$95 \% \mathrm{CI}$} \\
\hline & \multicolumn{2}{|c|}{$\geq 50 \%$} & \multicolumn{2}{|c|}{$<\mathbf{5 0} \%$} & & & \\
\hline & $n$ & $\%$ & $n$ & $\%$ & & & \\
\hline Psychomotor agitation & 5 & 6.2 & 14 & 4 & 1.5 & 0.37 & $0.5-4.4$ \\
\hline Transient ischemic episode & 2 & 2.5 & 0 & - & - & 0.03 & - \\
\hline Cognitive abnormalities & 5 & 9.4 & 5 & 2.3 & 4.9 & 0.01 & $2.9-5.2$ \\
\hline Stroke & 2 & 2.5 & 4 & 1.1 & 2.1 & 0.31 & $0.3-12$ \\
\hline Death & 19 & 22.6 & 35 & 9.6 & 2.7 & 0.001 & $1.4-5.1$ \\
\hline
\end{tabular}

$\mathrm{CI}=$ confidence interval; $\mathrm{OR}=$ odds ratio.

In the multivariate analysis, only $\mathrm{CAS} \geq 50 \%$ remained as an independent predictor of mortality. Obesity showed a protective effect against mortality (Table 3 ).

\section{DISCUSSION}

Clinically, CAS was confirmed as an independent predictor of mortality. We could not explain the finding that obesity, through some unknown mechanism has a protective effect against mortality. Another important aspect in our study was that, although the diagnosis of carotid bruit presented low sensitivity (34\%), patients with this finding had a 4.24 times greater risk for CAS, which reinforces the importance of preoperative clinical examination. Carotid bruit is the most accessible physical finding in clinical practice, in spite of an important limitation: according to data from the NASCET study [15], carotid bruit has shown a sensitivity of $63 \%$ and a specificity of $61 \%$. Those authors concluded that the clinical significance of carotid bruit should not be overestimated due to its low specificity. Moreover, because of the low sensitivity of the finding, it may be absent in up to one third of the patients with CAS [16].

The number of deaths (12\%) struck us as being high for CABG patients, although there were elective and nonelective surgeries and use of CPB in all cases. It may be that this was a particularly high risk group of patients.

Studies describing the management of cerebrovascular disease have clearly shown that carotid artery surgery associated with optimal clinical treatment significantly reduced the risk for stroke and death when compared with optimal clinical treatment only in symptomatic patients presenting atherosclerotic plaques in the carotid bifurcation and stenosis between 70 and 99\% [17]. Multicentric studies used as reference in our hospital have shown an absolute reduction $>15 \%$ in the risk for combined death and stroke in 5 years, even with a perioperative risk of $6 \%$ and a number requiring treatment of 6.3 (95\%CI 5-9) $[11,15]$. On the other hand, patients without neurological symptoms such as strokes or transient ischemic attacks submitted to surgical treatment presented an absolute risk reduction of approximately 5.5\% in five years $[18,19]$. CABG, when performed in patients with severe CAS, is associated with strokes in $2-3 \%$ of the patients; this incidence increased to $7 \%$ when $\mathrm{CABG}$ is combined with valve surgery [20]. Off-pump CABG has not shown any effect on mortality, infarction or stroke in one year [21], but prophylactic cerebrovascular interventions and clinical treatment of atheromatous aorta have been suggested to reduce the incidence of stroke [22].

Intensive management of atheromatous aorta and cerebral hemodynamics via hemodilution, administration of lidocaine using cardioplegic solution [23] in patients eligible for CABG should be focused on those with clinical CAS. Submitting these patients to on-pump could result in a significant reduction in distal blood pressure and flow, potentially causing an ischemic event such as a vasodilation response to low perfusion [24].

Ultrasound can also help in the diagnosis and follow-up of patients submitted to the conservative treatment, because CAS is per se a risk predictor, especially of vascular death. The detection of significant CAS may allow changing the surgical strategy with acceptable risks and costs, both in

Table 3. Independent Predictors of Mortality in Patients Scheduled for CABG

\begin{tabular}{|l|c|c|c|}
\hline \multicolumn{1}{|c|}{ Variable } & OR & 95\%CI & \multicolumn{1}{c|}{ P } \\
\hline Carotid stenosis $\geq 50 \%$ & 2.8 & $1.3-6$ & 0.005 \\
\hline Left main coronary trunk lesion & 0.5 & $0.2-1$ & $0.1-0.8$ \\
\hline Obesity & 0.4 & $0.8-6.1$ & 0.02 \\
\hline Renal failure & 2.2 & 0.09 \\
\hline
\end{tabular}

$\mathrm{CABG}=$ coronary artery bypass grafting; $\mathrm{CI}=$ confidence interval; $\mathrm{OR}=$ odds ratio.

Controlled variables: age, diabetes, hypertension, sedentarism, obesity, family history of CVD, PVD, and smoker. 
concomitant procedures [25] and in carotid revascularization followed by $\mathrm{CABG}$, even in asymptomatic patients.

We believe that ultrasound for CAS is valid and should be performed in all patients scheduled for CABG in our hospital. According to the authors, whenever significant CAS is diagnosed, CABG should be planned in conjunction or after treatment for carotid disease. Other authors believe that ultrasound should be restricted to high-risk patients, namely those aged $>65$ years with cervical bruit, previous strokes or transient ischemic episodes, PVD [26], hypertension, left main coronary stenosis, a history of smoking, diabetes, and atherosclerotic disease of the aortic arch [27].

Carotid artery ultrasound was chosen as the tool in our study because it is a non-invasive complementary method widely used in screening for carotid atherosclerotic disease, with sensitivity and specificity rates that are similar to those obtained with magnetic resonance angiography [28]. The latter method remains as the traditional gold standard for cerebrovascular assessment in symptomatic patients. However, the high cost of MRI angiography and the associated risk of stroke and other complications have increasingly motivated the use of non-invasive screening methods.

Cerebrovascular disease has to be closely monitored, and new techniques such as endovascular management [29] and pharmacological treatment of atherosclerosis are at an advanced stage of development. The search for reductions in CABG-related morbidity, mortality, and costs should include adequate preoperative investigation. Focusing efforts on the judicious use of the diagnostic methods available and the consequent reduction in costs and complications would most probably result in a more satisfactory treatment.

One limitation of the present study was the lack of neuropsychological tests as part of preoperative screening, since these tests can detect minimal abnormalities in mental status, cognitive function, and behavior. Moreover, our sample consisted of patients treated at one healthcare facility only, which may limit the extrapolation of results to the general population.

\section{CONCLUSION}

Our findings showed that CAS was an independent predictor of mortality in the postoperative in-hospital period of patients submitted to CABG. There were elective and nonelective scheduled patients in our sample, and it requires further study.

\section{DISCLOSURE}

The authors declare no conflict of interest.

\section{CONFLICT OF INTEREST}

The authors confirm that this article content has no conflicts of interest.

\section{ACKNOWLEDGEMENT}

None declared.

\section{REFERENCES}

[1] The Task Force on Myocardial Revascularization of the European Society of Cardiology (ESC) and the European Association for Cardio-Thoracic Surgery (EACTS). Guidelines on myocardial revascularization. Eur J Cardiothorac Surg 2010; 38: 1-52.

[2] Roques F, Nashef SA, Michel P, et al. Risk factors and outcome in European cardiac surgery: analysis of the EuroSCORE multinational database of 19030 patients. Eur J Cardiothorac Surg 1999; 15: 816-22.

[3] Scrutinio D, Giannuzzi P. Comorbidity in patients undergoing coronary artery bypass graft surgery: impact on outcome and implications for cardiac rehabilitation. Eur J Cardiovasc Prev Rehabil 2008; $15: 379-85$.

[4] Ghosh J, Murray D, Khwaja N, Murphy MO, Walker MG. The influence of asymptomatic significant carotid disease on mortality and morbidity in patients undergoing coronary artery bypass surgery. Eur J Vasc Endovasc Surg 2005; 29: 88-90.

[5] Timaran $\mathrm{CH}$, Rosero EB, Smith ST, Valentine RJ, Modrall JG, Clagett GP. Trends and outcomes of concurrent carotid revascularization and coronary bypass. J Vasc Surg 2008; 48: 355-61.

[6] Renton S, Hornick P, Taylor KM, Grace PA. Rational approach to combined carotid and ischaemic heart disease. Br J Surg 2005; 84: 1503-10.

[7] Dubinsky RM, Lai SM. Mortality from combined carotid endarterectomy and coronary artery bypass surgery in the US. Neurology 2007; 68: 195-7.

[8] Mullenix PS, Martin MJ, Steele SR, et al. Rapid high-volume population screening for three major risk factors of future stroke: phase I results. Vasc Endovasc Surg 2006; 40: 177-87.

[9] Braun RM, Bertino RE, Milbrandt J, Bray M. Ultrasound imaging of carotid artery stenosis: application of the Society of Radiologists in Ultrasound Consensus Criteria to a Single Institution Clinical Practice. Ultrasound Q 2008; 24: 161-6.

[10] Grant EG, Benson CB, Moneta GL, et al. Carotid artery stenosis: grayscale and Doppler ultrasound diagnosis - society of radiologists in ultrasound consensus conference. Radiology 2003; 229: 340-6.

[11] Randomized trial of endarterectomy for recently symptomatic carotid stenosis: final results of the MRC European Carotid Surgery Trial (ECST). Lancet 1998; 351: 1379-87.

[12] Bassan MM, Oatfield R, Hoffman I, Matloff J, Swan HJ. New Q waves after aortocoronary bypass surgery. Unmasking of an old infarction. N Engl J Med 1974; 290: 349-53.

[13] Klatte K, Chaitman BR, Theroux P, et al. GUARDIAN Investigators (The GUARD during Ischemia Against Necrosis). Increased mortality after coronary artery bypass graft surgery is associated with incrased levels of postoperative creatine kinase-myocardial band isoenzyme release.Results from the GUARDIAN trial. J Am Coll Cardiol 2001; 38: 1070-7.

[14] Januzzi JL, Lewandrowski K, MacGillivray TE, et al. A comparison of cardiac troponin $\mathrm{T}$ and creatine kinase-MB for patient evaluation after cardiac surgery. J Am Coll Cardiol 2002; 39: 151823.

[15] North American Symptomatic Carotid Endarterectomy Trial Collaborators. Beneficial effect of carotid endarterectomy in symptomatic patients with high-grade carotid stenosis. N Engl J Med 1991; 325: 445-53.

[16] Murie JA, Sheldon CD, Quin RO. Carotid artery bruit: Association with internal carotid stenosis and intraluminal turbulence. Br J Surg 2005; 71: 50-2.

[17] Biller J, Feinberg WM, Castaldo JE, et al. Guidelines for carotid endarterectomy. A statement for healthcare professionals from a special writing group of the stroke council, American Heart Association. Circulation 1998; 97: 501-9.

[18] Executive committee for the asymptomatic carotid atherosclerosis study group. Carotid endarterectomy for patients with asymptomatic internal carotid artery stenosis. JAMA 1995; 273: 1421-8.

[19] Halliday AW, Thomas DJ, Marro J, et al. Asymptomatic carotid surgery trial (ACST). Prevention of disabling and fatal strokes by successful carotid endarterectomy in patients without recent neurological symptoms: randomised controlled trial. Lancet 2004; 363 : 1491-502. 
[20] Fukuda I, Gomi S, Watanabe K, Seita J. Carotid and aortic screening for coronary artery bypass grafting. Ann Thorac Surg 2000; 70: 2034-9.

[21] Feng ZZ, Shi J, Zhao XW, Xu ZF. Meta-analysis of on-pump and off-pump coronary arterial revascularization. Ann Thorac Surg 2009; 87: 757-65.

[22] Nakamura M, Okamoto F, Nakanishi K, et al. Does intensive management of cerebral hemodynamics and atheromatous aorta reduce stroke after coronary artery surgery? Ann Thorac Surg 2008; 85: 513-9.

[23] Ghafari R, Baradari AG, Firouzian A, et al. Cognitive deficit in first-time coronary artery bypass graft patients: a randomized clinical trial of lidocaine versus procaine hydrochloride. Perfusion 2012; 27: 320-5.

[24] Zembala MO, Filipiak K, Ciesla D, et al. Surgical treatment of left main disease and severe carotid stenosis: does the off-pump technique provide a better outcome? Eur J Cardiothorac Surg 2012; 42: $1-8$.
[25] Iyem H, Buket S. Early results of combined and staged coronary bypass and carotid endarterectomy in advanced age patients in single centre. Open Cardiovasc Med J 2009; 3: 8-14.

[26] Durand DJ, Perler BA, Roseborough GS, et al. Mandatory versus selective preoperative carotid screening: a retrospective analysis. Ann Thorac Surg 2004; 78: 159-66.

[27] Mahmoudi M, Hill PC, Xue Z, et al. Patients with severe asymptomatic carotid artery stenosis do not have a higher risk of stroke and mortality after coronary artery bypass surgery. Stroke 2011 42: $2801-5$

[28] Hammond CJ, McPherson SJ, Patel JV, Gough MJ. Assessment of apparent internal carotid occlusion on ultrasound: prospective comparison of contrast-enhanced ultrasound, magnetic resonance angiography and digital subtraction angiography. Eur J Vasc Endovasc Surg 2008; 35: 405-12.

[29] Bayram NA, Bozkurt E, Ayhan H, et al. Early outcomes of carotid artery stenting. Perfusion 2012; 27: 146-9.

(C) Rosa et al.; Licensee Bentham Open.

This is an open access article licensed under the terms of the Creative Commons Attribution Non-Commercial License (http://creativecommons.org/licenses/ by-nc/3.0/) which permits unrestricted, non-commercial use, distribution and reproduction in any medium, provided the work is properly cited. 